\title{
PERSPECTIVE
}

\section{Rho deep in thought}

\author{
Rachel McMullan and Stephen J. Nurrish ${ }^{1}$ \\ Medical Research Council (MRC) Cell Biology Unit, MRC Laboratory for Molecular Cell Biology and Department of \\ Pharmacology, University College, London WC1E 6BT, United Kingdom
}

Neuronal communication underlies all aspects of brain function, including learning, memory, and consciousness. How neurons communicate is controlled by both the formation of neuronal connections during neural development and the regulation of neuronal activity in the adult brain. Rho GTPases have a well-known role in neuronal development, and recent studies published in Genes \& Development (Steven et al. 2005; McMullan et al. 2006) have demonstrated that they also regulate neuronal activity in the adult brain-at least in Caenorhabditis elegans. Rho in C. elegans acts as part of a network of $\mathrm{G} \alpha_{\mathrm{q}}$ pathways that increase neuronal activity by regulating both production and destruction of the second messenger diacylglycerol (DAG), which is a regulator of synaptic vesicle release. In this issue of Genes \& Development, Williams et al. (2007) demonstrate that $\mathrm{G} \alpha_{\mathrm{q}}$ acts via the UNC-73RhoGEF to increase Rho activity in neurons, and thus increase levels of DAG. The targets of DAG are known and, in one case, a pathway stretching from binding of ligand on the cell surface to changes in synaptic vesicle priming has been mapped out.

$\mathbf{G} \boldsymbol{\alpha}_{\mathrm{o}}$ and $\mathbf{G} \boldsymbol{\alpha}_{\mathrm{q}}$ antagonistically control neuronal activity

C. elegans has proven to be an excellent model to study how changes in neuronal activity regulate behavior. Currently, the C. elegans cholinergic motorneuron represents the best-understood example of multiple G-protein signaling pathways acting within a single neuron to regulate neuronal activity. C.elegans has $21 \mathrm{G} \alpha$ subunits. These include one ortholog of each mammalian $\mathrm{G} \alpha$ family: GOA-1 $\left(\mathrm{G} \alpha_{\mathrm{i} / \mathrm{o}}\right)$, EGL-30 $\left(\mathrm{G} \alpha_{\mathrm{q}}\right)$, GSA-1 $\left(\mathrm{G} \alpha_{\mathrm{s}}\right)$, and GPA-12 $\left(\mathrm{G} \alpha_{12}\right)$. The remainder are most closely related to $\mathrm{G}_{\mathrm{i} / \mathrm{o}}$, but are specific to C. elegans. All four of the $\mathrm{G} \alpha$ orthologs modulate neuronal activity-most commonly, locomotion and acetylcholine (ACh) release. The first two $\mathrm{G}$ proteins identified as regulators of $C$. elegans neuronal activity were $\mathrm{G} \alpha_{\mathrm{o} / \mathrm{i}}$ (GOA-1, henceforth referred to as $\mathrm{G} \alpha_{\mathrm{o}}$ ) and $\mathrm{G} \alpha_{\mathrm{q}}$ (EGL-30).

$\mathrm{G} \alpha_{\mathrm{o}}(\mathrm{goa}-1)$ was the first G-protein $\alpha$ subunit shown to regulate C. elegans behavior (Mendel et al. 1995; Segalat et al. 1995). G $\alpha_{\mathrm{o}}$ mutants have increased locomotion, egg

${ }^{1}$ Corresponding author.

E-MAIl s.nurrish@ucl.ac.uk; FAX 44-20-76797805.

Article is online at http://www.genesdev.org/cgi/doi/10.1101/gad.1615807. laying, and ACh release, and are resistant to some effects of serotonin on behavior. The increased locomotion of $\mathrm{G} \alpha_{\mathrm{o}}$ mutant animals is referred to as the hyper phenotype. Expression of constitutively active $\mathrm{G} \alpha_{\mathrm{o}}$ in the cholinergic motorneurons decreases locomotion and $\mathrm{ACh}$ release. Loss of $\mathrm{G} \alpha_{\mathrm{o}}$ specifically in the cholinergic motorneurons causes the same increases in locomotion and ACh release as caused by a complete loss of $\mathrm{G} \alpha_{\mathrm{o}}$ in all cells (Nurrish et al. 1999). Thus, $\mathrm{G} \alpha_{\mathrm{o}}$ acts within the cholinergic motorneurons to decrease neuronal activity, which we shall define as rate of locomotion and/or rate of $\mathrm{ACh}$ release.

$\mathrm{G} \alpha_{\mathrm{q}}($ egl-30) mutations have decreased locomotion, egg laying, and ACh release, and are resistant to the lethal effects of the muscarinic agonist arecoline or the acetylcholinesterase inhibitor aldicarb (Trent et al. 1983; Brundage et al. 1996; Miller et al. 1996, 1999; HajduCronin et al. 1999; Lackner et al. 1999). The decreased locomotion of $\mathrm{G} \alpha_{\mathrm{q}}$ mutant animals is referred to as the lethargic phenotype. Expression of activated $\mathrm{G} \alpha_{\mathrm{q}}$ in the cholinergic motorneurons increases both locomotion rate and ACh release (Lackner et al. 1999), which is the opposite effect of $\mathrm{G} \alpha_{\mathrm{o}}$. This suggests that $\mathrm{G} \alpha_{\mathrm{q}}$ and $\mathrm{G} \alpha_{\mathrm{o}}$ act antagonistically in cholinergic motorneurons to control neuronal activity: $\mathrm{G} \alpha_{\mathrm{q}}$ increases neuronal activity, whereas $\mathrm{G} \alpha_{\mathrm{o}}$ decreases neuronal activity (Fig. 1).

\section{$\mathrm{G} \alpha_{\mathrm{o}}$ and $\mathrm{G} \alpha_{\mathrm{q}}$ antagonistically regulate levels of DAG}

The key to understanding how $\mathrm{G} \alpha_{\mathrm{o}}$ and $\mathrm{G} \alpha_{\mathrm{q}}$ antagonistically regulate neuronal activity came with the cloning of DGK-1 (Nurrish et al. 1999). Both $\mathrm{G}_{\mathrm{o}}$ and $d g k-1 \mathrm{mu}-$ tants were identified in the screen for resistance to serotonin inhibition of locomotion. $d g k-1$ mutants were also identified as suppressors of a constitutively active $\mathrm{G} \alpha_{\mathrm{o}}$ (Hajdu-Cronin et al. 1999; Nurrish et al. 1999). Both G $\alpha_{o}$ and $d g k-1$ mutants have increased locomotion and ACh release. DGK-1 encodes a DAG kinase, which phosphorylates the membrane-bound second messenger DAG, converting it to another membrane-bound second messenger, Phosphatidic acid (PA). dgk-1 mutants are predicted to have elevated levels of DAG and lowered levels of PA. Addition of the DAG analog PMA (a phorbol ester) causes wild-type animals to have the same phenotype as $d g k-1$ mutants (Lackner et al. 1999; Miller et al. 1999; Nurrish et al. 1999), which suggests that the hyperactive locomotion and egg laying of $d g k-1$ animals 


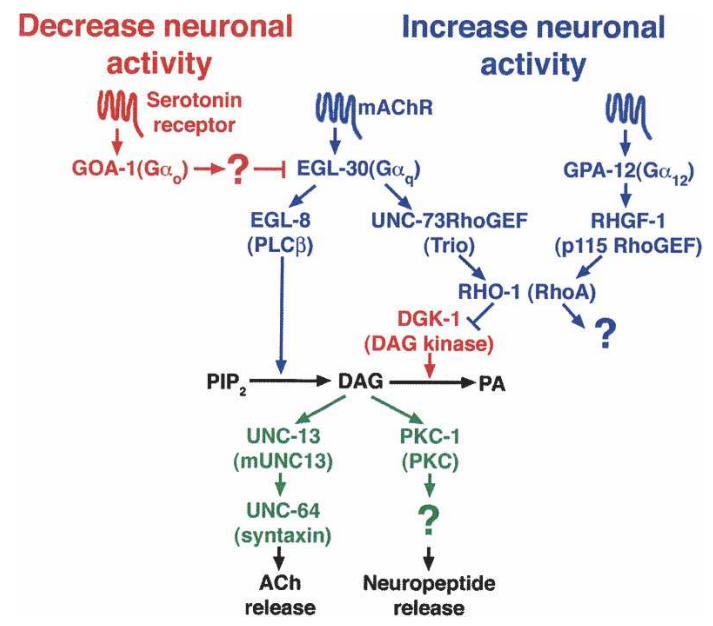

Figure 1. Multiple G proteins control the production and destruction of DAG to regulate neuronal activity. A model for G-protein networks acting within C. elegans cholinergic motorneurons to regulate neuronal activity. Shown in blue are those proteins that increase neuronal activity (as defined by increases in locomotion and/or ACh release), whereas those in red decrease neuronal activity. In green are downstream effectors of DAG. DAG is formed by the hydrolysis of PIP2, and DAG is removed by phosphorylation to form PA. C. elegans protein names are shown with mammalian orthologs in brackets. Not shown is $\mathrm{G} \alpha_{\mathrm{s}}$, whose role in control of cholinergic motorneuron activity remains unclear.

results from an excess of DAG. G $\alpha_{o}$ mutants, which closely resemble $d g k-1$ mutants, also have increased levels of DAG, specifically at neurotransmitter release sites (Nurrish et al. 1999). A role for DAG is further supported by the cloning of PLC $\beta$ egl-8. PLC $\beta$ egl-8 mutants have decreased locomotion, ACh release, and egg laying, which is similar to $\mathrm{G} \alpha_{\mathrm{q}}$ mutants (Trent et al. 1983; Lackner et al. 1999; Miller et al. 1999). EGL-8 is a PLC $\beta$ that, when activated by $\mathrm{G} \alpha_{\mathrm{g}}$, hydrolyzes Phosphatidylinositol $(4,5)$-bisphosphate (PIP2) into DAG and IP3; hence, PLC $\beta$ egl-8 mutants are predicted to have decreased levels of DAG. The lethargic locomotion and egg-laying phenotypes of both $\mathrm{G} \alpha_{\mathrm{q}}$ and PLC $\beta$ egl-8 mutants are completely suppressed by addition of PMA. Thus, mutants with increased levels of DAG $\left(\mathrm{G}_{\mathrm{o}}\right.$ and $\left.d g k-1\right)$ are hyper, whereas mutants with decreased levels of DAG $\left(\mathrm{G}_{\mathrm{q}}\right.$ and PLC $\beta$ egl-8) are lethargic. These data suggest a model in which $\mathrm{G} \alpha_{\mathrm{q}}$ and $\mathrm{G} \alpha_{\mathrm{q}}$ act within the cholinergic motorneurons to antagonistically control levels of the second messenger DAG. Increases in DAG stimulate locomotion and ACh release (Fig. 1).

How is it that DAG regulates ACh release? A series of studies by the Kaplan laboratory (Lackner et al. 1999; Nurrish et al. 1999; Sieburth et al. 2006) demonstrated that both UNC-13 and PKC-1 are required for DAG-mediated increases in cholinergic motorneuron activity. In mammals, UNC-13 and PKC homologs are also required for DAG-mediated increases in neuronal activity. In mammalian neurons, UNC-13 and PKC act together such that mutations in one fully block the effects of PMA (Rhee et al. 2002; Wierda et al. 2007). However, in
C. elegans UNC-13 and PKC-1 act in parallel such that a mutation in both is required to completely block PMA stimulation of neuronal activity. It is possible that different neurons of both the C. elegans and mammalian brain have differences in the integration of UNC-13 and PKC-1 signaling; alternatively, DAG effectors may be used differently in mammalian and C. elegans neurons to regulate neuronal activity.

UNC-13 binds to and positively regulates one of the $C$. elegans syntaxins, UNC-64, to promote synaptic vesicle docking and priming (although UNC-13 is likely to have other effectors as well) (Richmond et al. 2001; Madison et al. 2005; McEwen et al. 2006; Hammarlund et al. 2007). Thus, a pathway has been established stretching from the receiving of extracellular signals (activation of $\mathrm{G} \alpha_{\mathrm{q}}$-coupled receptors by arecoline) all the way to the core synaptic release machinery (Fig. 1).

\section{RHO-1 regulates neuronal activity}

C. elegans Rho GTPases include one Rho (RHO-1), one Cdc42 (CDC-42), two Rac (RAC-1, RAC-2), and one intermediate by homology between Cdc42 and Rac (MIG2 ). Evidence that RHO-1 is involved with regulation of neuronal activity first came from mutation of the RhoGEF domain of unc-73 (Steven et al. 2005). UNC-73 is an ortholog of mammalian Trio. These proteins contain separate RacGEF and RhoGEF domains that activate Rac and Rho GTPases, respectively. Both GEF domains can be present in the same protein or in separate proteins as a result of alternative splicing. Mutations in the UNC73RacGEF domain result in defective axon guidance (Steven et al. 1998). Steven et al. (2005) isolated a deletion in the UNC-73RhoGEF domain that still allows expression of proteins carrying a functional UNC73RacGEF domain. Loss of UNC-73RhoGEF in the nervous system causes reduced locomotion and egg laying; the egg-laying defect is so severe that eggs hatch within the parent, resulting in the "bag of worms" phenotype. UNC-73RhoGEF mutations are very similar to severe loss-of-function $\mathrm{G} \alpha_{\mathrm{q}}$ mutations; however, unlike $\mathrm{G} \alpha_{\mathrm{q}}$ mutations, the UNC-73RhoGEF mutation causes only a small defect in ACh release. Nontheless, these data demonstrate for the first time that a RhoGEF, and thus RHO-1, stimulates neuronal activity in C. elegans.

At the same time, the Nurrish laboratory (McMullan et al. 2006) set out to test whether neuronal activity is regulated by control of DAG removal. DAG is removed by DAG kinases, which include DGK-1. The human ortholog of DGK-1, DGK $\theta$, binds to and is inactivated by RhoA (Houssa et al. 1999). This interaction is conserved in C. elegans. Expression of constitutively active RHO-1 in the cholinergic motorneurons increases locomotion and ACh release. Thus, increased RHO-1 signaling mimics addition of PMA or a mutation in $d g k-1$. In contrast, inhibition of endogenous RHO- 1 in the cholinergic motorneurons decreases locomotion and ACh release. As with $\mathrm{G} \alpha_{\mathrm{o}}$ and $d g k-1$ mutants, activated RHO-1 increases levels of DAG. These results are consistent with a model where RHO-1 inhibits DGK-1 activity in the cholinergic 
motorneurons; this results in a rise of DAG and, thus, an increase in neuronal activity (Fig. 1).

Completing the integration of RHO-1 into G-protein control of neuronal activity, Williams et al. (2007) identified RHO-1 as a downstream effector of $\mathrm{G} \alpha_{\mathrm{q}}$ (Fig. 1). Although the PLC $\beta$ EGL-8 acts downstream from $\mathrm{G} \alpha{ }_{\mathrm{q}}$, it is clear that PLC $\beta$ EGL-8 is not the only $\mathrm{G} \alpha_{\mathrm{q}}$ effector. $\mathrm{G}_{\mathrm{q}}$ mutants grow very slowly and null mutants are barely alive, whereas null PLC $\beta$ egl-8 mutants are healthy and grow normally. Also, expression of activated $\mathrm{G} \alpha_{\mathrm{q}}$ in the cholinergic motorneurons increases both locomotion and ACh release, and these effects are only partially suppressed by PLC $\beta$ egl-8 mutants (Lackner et al. 1999; Miller et al. 1999). Screens for the missing $\mathrm{G}_{\mathrm{q}}$ effector identify mutations in unc-73 specific for the UNC-73RhoGEF transcripts. PLC $\beta$ egl-8; unc-73RhoGEF double mutants closely resemble the $\mathrm{G} \alpha_{\mathrm{q}}$-null mutants. Both are almost completely paralyzed and grow very poorly, suggesting that $\mathrm{G} \alpha_{\mathrm{q}}$ signals through both PLC $\beta$ EGL-8 and UNC-73RhoGEF. However, only PLC $\beta$ egl-8 mutants have a strong reduction in ACh release, and only unc-73RhoGEF mutants have the severe "bag of worms" egg-laying defect, both of which are observed in $\mathrm{G} \alpha_{\mathrm{q}}$ mutants. Thus, $\mathrm{G} \alpha_{\mathrm{q}}$ signals more strongly through PLC $\beta$ EGL-8 to regulate ACh release. In contrast, $\mathrm{G \alpha}_{\mathrm{q}}$ signals more strongly through UNC-73RhoGEF to regulate egg laying. The differing effects of these two $G \alpha_{\mathrm{q}}$ effector pathways may reflect differences in the downstream targets of PLC $\beta$ EGL-8 and UNC-73RhoGEF. For example, PLC $\beta$ produces $\mathrm{IP}_{3}$, which acts to increase intracellular $\mathrm{Ca}^{2+}$, whereas RHO-1 signaling is likely to alter actin dynamics.

\section{Multiple RhoGEFs regulate neuronal activity}

UNC-73RhoGEF belongs to a new class of RhoGEFs regulated by G proteins (Lutz et al. 2005, 2007; Rojas et al. 2007). The study by Williams et al. (2007) represents the first in vivo evidence that this class of RhoGEFs is important for $\mathrm{G}_{\mathrm{q}}$ signaling. Another class of RhoGEFs that are regulated by G-proteins are those containing a Regulator of G-protein Signaling (RGS) domain. C. elegans has a single RGS-containing RhoGEF, RHGF-1, which is homologous to mammalian p115 RGSRhoGEF and is regulated by $\mathrm{G} \alpha_{12}$. In C. elegans, expression of activated $\mathrm{G} \alpha_{12}$ in the cholinergic motorneurons increases levels of ACh release in a RHGF-1- and RHO-1dependent manner. (Hiley et al. 2006). However, null mutations in both $\mathrm{G}_{12}$ and RHGF-1 have no effect on ACh release under standard laboratory conditions. Thus, it is unclear under what conditions $\mathrm{G} \alpha_{12}$ signaling to RHO- 1 is active.

Both UNC-73 and RHGF-1 RhoGEFs can stimulate RHO-1 to increase neuronal activity, but are these the only RhoGEFs active in the adult nervous system? Inhibition of endogenous RHO-1 within the cholinergic motorneurons causes a strong reduction in both locomotion and ACh release. This suggests that a RhoGEF must activate RHO-1 in the cholinergic motorneurons. However, mutations in either UNC-73RhoGEF or RHGF-1 have a very small decrease of ACh release. Perhaps these two RhoGEFs act redundantly within the cholinergic motorneurons? Alternatively, there are 21 Dbl Homology domain-containing RhoGEFs in C. elegans; perhaps other RhoGEFs also regulate neuronal activity? Analysis of an unc-73RhoGEF;rhgf-1 double mutant will answer this question.

\section{Does $\mathrm{G} \alpha_{\mathrm{q}}$ signal via PLC $\beta$ EGL-8 and UNC-73RhoGEF in the same cells?}

An important question is whether or not $\mathrm{G} \alpha_{\mathrm{q}}$ signals through PLC $\beta$ EGL-8 and UNC-73RhoGEF in the same cells. Several site-of-action experiments have been performed on many of the proteins discussed so far. Transgenes expressing activated versions of $\mathrm{G} \alpha_{\mathrm{q}}, \mathrm{G} \alpha_{\mathrm{o}}$, and RHO-1 in the cholinergic motorneurons alter both locomotion and ACh release (Lackner et al. 1999; Nurrish et al. 1999; McMullan et al. 2006). Inactivation of endogenous $\mathrm{G} \alpha_{\mathrm{o}}$ or RHO- 1 in the cholinergic motorneurons is sufficient to alter both locomotion and ACh release (Nurrish et al. 1999; McMullan et al. 2006). Cholinergic motorneuron-specific expression of PLC $\beta$ EGL-8 or DGK-1 in egl-8 or $d g k-1$ mutants, respectively, is sufficient to rescue their locomotion and ACh release defects (Lackner et al. 1999; Nurrish et al. 1999). Thus, $\mathrm{G} \alpha_{\mathrm{q}^{\prime}}$ $\mathrm{G} \alpha \alpha_{\mathrm{o}}$, PLC $\beta$ EGL-8, DGK-1, and RHO-1 all act within the cholinergic motorneurons to regulate locomotion and ACh release. However, $\mathrm{G} \alpha_{\mathrm{q}}, \mathrm{G} \alpha_{\mathrm{o}}$, and RHO-1 may also be required in additional neurons for wild-type levels of locomotion and ACh release. Expression of UNC73RhoGEF only in the cholinergic motorneurons fails to rescue the decreased locomotion of unc-73RhoGEF mutants, although UNC-73RhoGEF expression from a panneural promoter does rescue locomotion (Steven et al. 2005; Williams et al. 2007). Thus, for wild-type locomotion, UNC-73RhoGEF is required either in neuronal cells other than the cholinergic motorneurons, or in both the cholinergic motorneurons and another neuronal cell type. Cholinergic motorneuron expression of activated $\mathrm{G}_{\mathrm{q}}$ causes an increase in locomotion and $\mathrm{ACh}$ release that is only partially suppressed by a PLC $\beta$ egl-8 mutation (Lackner et al. 1999). Therefore, UNC-73RhoGEF must have a role in the cholinergic motorneurons, or a third pathway downstream from $\mathrm{G} \alpha_{\mathrm{q}}$ remains to be discovered. It appears that all cells that express $\mathrm{G} \alpha_{\mathrm{q}}$ also express both PLC $\beta$ EGL-8 and UNC-73RhoGEF. Thus it is unclear why in some neuronal cells UNC-73RhoGEF is required but PLC $\beta$ EGL-8 is not. One possible explanation is that, in some neurons, PLC $\beta$ EGL- 8 acts redundantly with another $\mathrm{G}_{\mathrm{q}_{\mathrm{q}}}$-regulated PLC, possibly the PLC $\beta$-like PLC-2, although expression of PLC-2 has not been observed in the nervous system.

\section{There is still a lot we do not know about G-protein regulation of neuronal activity}

We still do not understand how $\mathrm{G} \alpha_{\mathrm{o}}$ regulates neuronal activity. $d g k-1$ mutants suppress activated $\mathrm{G}_{\mathrm{o}}$, but as 
yet there is no evidence that $\mathrm{G} \alpha_{\text {o }}$ regulates DGK-1. As $\mathrm{G} \alpha_{\mathrm{q}} ; \mathrm{G} \alpha_{\mathrm{o}}$ double mutants more closely resemble $\mathrm{G} \alpha_{\mathrm{q}}$ mutants, it has been suggested that $\mathrm{G} \alpha_{\mathrm{o}}$ acts upstream of $\mathrm{G} \alpha_{\mathrm{q}}$. It is possible that $\mathrm{G} \alpha_{\mathrm{o}}$ targets other aspects of neuronal function, such as ion channels. However, the accumulation of DAG at release sites in $\mathrm{G} \alpha_{\mathrm{o}}$ mutants suggests that some aspect of DAG production or destruction must be regulated by $\mathrm{G} \alpha_{\mathrm{o}}$ (Nurrish et al. 1999). Williams et al. (2007) isolated mutations in unc-108, a RabGTPase, in the same $\mathrm{G} \alpha_{\mathrm{o}}$ mutant suppressor screen that identified UNC-73RhoGEF mutations. Hopefully, identification of $\mathrm{G} \alpha_{\mathrm{o}}$ mutant suppressors will uncover the targets of $\mathrm{G} \alpha_{\mathrm{o}}$ signaling.

Another important question is: What are the downstream targets of RHO-1? DGK-1 and UNC-13 are important for $\mathrm{RHO}-1$ regulation of $\mathrm{ACh}$ release, but they only account for part of RHO-1's effects; this suggests that at least one additional pathway downstream from RHO-1 must exist (McMullan et al. 2006). Perhaps RHO-1 targets other components of the synaptic vesicle cycle. Alternatively, changes in the actin cytoskeleton may be required for efficient synaptic vesicle release.

We also do not know the downstream effector of PKC1. PKC-1 is required for the full response to DAG, and it appears to stimulate neuropeptide release from the cholinergic motorneurons (Sieburth et al. 2006). Studies in mammalian neurons suggest that a likely target of PKC-1 is the neuromodulator UNC-18 (Wierda et al. 2007). However, attempts to block PKC-1 signaling in $C$. elegans by mutating UNC-18 have failed so far (Sieburth et al. 2006).

$\mathrm{G} \alpha_{\mathrm{s}}$ activation in the nervous system increases both locomotion and $\mathrm{ACh}$ release via activation of Protein Kinase A (Schade et al. 2005). Both $\mathrm{G} \alpha_{\mathrm{q}}$ and $\mathrm{G} \alpha_{\mathrm{s}}$ mutations strongly reduce locomotion, although $\mathrm{G} \alpha_{\mathrm{s}}$ mutations do not cause a defect in ACh release (Reynolds et al. 2005). It is unclear where $\mathrm{G} \alpha_{\mathrm{s}}$ acts, although cholinergic motorneuron expression of an activated adenylate cyclase, a $\mathrm{G} \alpha_{\mathrm{s}}$ effector, rescues locomotion in mutants defective for neuropeptide release (Charlie et al. 2006). This suggests that $\mathrm{G} \alpha_{\mathrm{s}}$, like $\mathrm{G} \alpha_{\mathrm{q}}$, Go, and $\mathrm{G} \alpha_{12}$, does play a role in the cholinergic motorneurons, and that all four $\mathrm{G}$ proteins can act within the same cell to modulate neuronal activity.

\section{A model for the human brain?}

G-protein signaling by both $\alpha$ and $\beta \gamma$ subunits regulates neuronal activity in the mammalian brain, although in most cases this is linked to changes in ion channel function (Wettschureck and Offermanns 2005). Typically, in mammalian neurons $G_{\mathrm{q}}$ signaling increases neuronal activity, whereas $\mathrm{G}_{\mathrm{o} / \mathrm{i}}$ signaling decreases it, as observed in C. elegans. Knockouts of $\mathrm{G} \alpha_{\mathrm{o}}$ or $\mathrm{G} \alpha_{\mathrm{q}}$ in mice do not alter gross brain morphology but do cause severe neurological defects, including hyperactive locomotion in the $\mathrm{G} \alpha_{\mathrm{o}}$ knockout (Jiang et al. 1998). Rho is also important in the human brain, as mutations in regulators and effectors of Rho GTPases are associated with mental retardation in humans (Govek et al. 2005). In mice, activation of Rho
GTPases improves learning and memory (Diana et al. 2007), while knockouts of Rho effectors impair it (Meng et al. 2002, 2005; Soderling et al. 2003). Rac acts presynaptically to regulate synaptic strength in Aplysia (Doussau et al. 2000; Humeau et al. 2002), and both Rac and Cdc42 induce exocytosis in mammalian secretory cells (Kowluru et al. 1997; Brown et al. 1998). A role for Rho in the regulation of mammalian neurotransmitter release is less clear. In PC12 cells, RhoB is required for potentiation of ACh release by lysophosphatidic acid (Ishida et al. 2004), and inhibition of Rho can inhibit potassiumevoked release (Komuro et al. 1996). In contrast, adrenalin release from PC12 cells has been reported to be independent of Rho (Wang et al. 2004) and, in some cases, Rho signaling may even act to inhibit release by stabilizing the actin cytoskeleton (Dillon and Goda 2005).

No conclusive links between $\mathrm{G} \alpha_{\mathrm{q}}$, Rho, and the synaptic vesicle cycle have been made in the mammalian brain. However, DAG is known to stimulate mammalian neurotransmitter release, and C. elegans will serve as an important model for understanding how DAG levels are regulated in mammalian neurons.

\section{The worm has a lot more to tell us}

Studies in C. elegans show that DAG is a critical regulator of neuronal activity, and that networks of G-protein signaling pathways exist to control both DAG production and destruction (Fig. 1). Recent advances have now placed Rho within those G-protein pathways that control DAG destruction. Although we know a great deal about how $G$ proteins regulate neuronal activity, there remain more components of these pathways to be discovered. Future work is also likely to integrate other types of pathways, such as receptor tyrosine kinases, into a better understanding of how neuronal activity is regulated. Particularly exciting is the recent use of genome-wide RNA interference screens to identify regulators of neuronal activity (Sieburth et al. 2005). Finding these pathways in C. elegans is likely to tell us a great deal more about how communication in our own brains is regulated.

\section{Acknowledgments}

We thank Alison Lloyd and Martin Raff for comments on the manuscript. We apologize to those authors whose work was left out due to space constraints.

\section{References}

Brown, A.M., O'Sullivan, A.J., and Gomperts, B.D. 1998. Induction of exocytosis from permeabilized mast cells by the guanosine triphosphatases Rac and Cdc42. Mol. Biol. Cell 9: 1053-1063.

Brundage, L., Avery, L., Katz, A., Kim, U.J., Mendel, J.E., Sternberg, P.W., and Simon, M.I. 1996. Mutations in a C. elegans Gq $\alpha$ gene disrupt movement, egg laying, and viability. Neuron 16: 999-1009.

Charlie, N.K., Schade, M.A., Thomure, A.M., and Miller, K.G. 2006. Presynaptic UNC-31 (CAPS) is required to activate the $\mathrm{G} \alpha_{s}$ pathway of the Caenorhabditis elegans synaptic signaling network. Genetics 172: 943-961. 
Diana, G., Valentini, G., Travaglione, S., Falzano, L., Pieri, M., Zona, C., Meschini, S., Fabbri, A., and Fiorentini, C. 2007. Enhancement of learning and memory after activation of cerebral Rho GTPases. Proc. Natl. Acad. Sci. 104: 636-641.

Dillon, C. and Goda, Y. 2005. The actin cytoskeleton: Integrating form and function at the synapse. Annu. Rev. Neurosci. 28: $25-55$.

Doussau, F., Gasman, S., Humeau, Y., Vitiello, F., Popoff, M., Boquet, P., Bader, M.F., and Poulain, B. 2000. A Rho-related GTPase is involved in $\mathrm{Ca}^{2+}$-dependent neurotransmitter exocytosis. J. Biol. Chem. 275: 7764-7770.

Govek, E.E., Newey, S.E., and Van Aelst, L. 2005. The role of the Rho GTPases in neuronal development. Genes \& Dev. 19: $1-49$.

Hajdu-Cronin, Y.M., Chen, W.J., Patikoglou, G., Koelle, M.R., and Sternberg, P.W. 1999. Antagonism between G(o) $\alpha$ and $\mathrm{G}(\mathrm{q}) \alpha$ in Caenorhabditis elegans: The RGS protein EAT-16 is necessary for $\mathrm{G}(\mathrm{o}) \alpha$ signaling and regulates $\mathrm{G}(\mathrm{q}) \alpha$ activity. Genes \& Dev. 13: 1780-1793.

Hammarlund, M., Palfreyman, M.T., Watanabe, S., Olsen, S., and Jorgensen, E.M. 2007. Open syntaxin docks synaptic vesicles. PLOS Biol. 5: e198. doi: 10.1371/journal. pbio.0050198.

Hiley, E., McMullan, R., and Nurrish, S.J. 2006. The G $\alpha_{12}-$ RGS RhoGEF-RhoA signalling pathway regulates neurotransmitter release in C. elegans. EMBO I. 25: 5884-5895.

Houssa, B., de Widt, J., Kranenburg, O., Moolenaar, W.H., and van Blitterswijk, W.J. 1999. Diacylglycerol kinase $\theta$ binds to and is negatively regulated by active RhoA. J. Biol. Chem. 274: 6820-6822.

Humeau, Y., Popoff, M.R., Kojima, H., Doussau, F., and Poulain, B. 2002. Rac GTPase plays an essential role in exocytosis by controlling the fusion competence of release sites. J. Neurosci. 22: 7968-7981.

Ishida, H., Zhang, X., Erickson, K., and Ray, P. 2004. Botulinum toxin type A targets RhoB to inhibit lysophosphatidic acidstimulated actin reorganization and acetylcholine release in nerve growth factor-treated PC12 cells. J. Pharmacol. Exp. Ther. 310: 881-889.

Jiang, M., Gold, M.S., Boulay, G., Spicher, K., Peyton, M., Brabet, P., Srinivasan, Y., Rudolph, U., Ellison, G., and Birnbaumer, L. 1998. Multiple neurological abnormalities in mice deficient in the G protein Go. Proc. Nat1. Acad. Sci. 95: 3269-3274.

Komuro, R., Sasaki, T., Takaishi, K., Orita, S., and Takai, Y. 1996. Involvement of Rho and Rac small G proteins and Rho GDI in $\mathrm{Ca}^{2+}$-dependent exocytosis from PC12 cells. Genes Cells 1: 943-951.

Kowluru, A., Li, G., Rabaglia, M.E., Segu, V.B., Hofmann, F., Aktories, K., and Metz, S.A. 1997. Evidence for differential roles of the Rho subfamily of GTP-binding proteins in glucose- and calcium-induced insulin secretion from pancreatic $\beta$ cells. Biochem. Pharmacol. 54: 1097-1108.

Lackner, M.R., Nurrish, S.J., and Kaplan, J.M. 1999. Facilitation of synaptic transmission by EGL-30 Gq $\alpha$ and EGL-8 PLC $\beta$ : DAG binding to UNC-13 is required to stimulate acetylcholine release. Neuron 24: 335-346.

Lutz, S., Freichel-Blomquist, A., Yang, Y., Rumenapp, U., Jakobs, K.H., Schmidt, M., and Wieland, T. 2005. The guanine nucleotide exchange factor p63RhoGEF, a specific link between Gq/11-coupled receptor signaling and RhoA. J. Biol. Chem. 280: 11134-11139.

Lutz, S., Shankaranarayanan, A., Coco, C., Ridilla, M., Nance, M., Vettel, C., Baltus, D., Evelyn, C., Neubig, R.R., Wieland, T., et al. 2007. Structure of the G $\alpha_{\mathrm{q}}-\mathrm{p} 63$ RhoGEF-RhoA complex reveals a conserved pathway for activation of RhoA by
GPCRs. Science (in press).

Madison, J.M., Nurrish, S., and Kaplan, J.M. 2005. UNC-13 interaction with syntaxin is required for synaptic transmission. Curr. Biol. 15: 2236-2242.

McEwen, J.M., Madison, J.M., Dybbs, M., and Kaplan, J.M. 2006. Antagonistic regulation of synaptic vesicle priming by Tomosyn and UNC-13. Neuron 51: 303-315.

McMullan, R., Hiley, E., Morrison, P., and Nurrish, S.J. 2006. Rho is a presynaptic activator of neurotransmitter release at pre-existing synapses in C. elegans. Genes \& Dev. 20: 65-76.

Mendel, J.E., Korswagen, H.C., Liu, K.S., Hajdu-Cronin, Y.M., Simon, M.I., Plasterk, R.H., and Sternberg, P.W. 1995. Participation of the protein Go in multiple aspects of behavior in C. elegans. Science 267: 1652-1655.

Meng, Y., Zhang, Y., Tregoubov, V., Janus, C., Cruz, L., Jackson, M., Lu, W.Y., MacDonald, J.F., Wang, J.Y., Falls, D.L., et al. 2002. Abnormal spine morphology and enhanced LTP in LIMK-1 knockout mice. Neuron 35: 121-133.

Meng, J., Meng, Y., Hanna, A., Janus, C., and Jia, Z. 2005. Abnormal long-lasting synaptic plasticity and cognition in mice lacking the mental retardation gene Pak3. J. Neurosci. 25: 6641-6650.

Miller, K.G., Alfonso, A., Nguyen, M., Crowell, J.A., Johnson, C.D., and Rand, J.B. 1996. A genetic selection for Caenorhabditis elegans synaptic transmission mutants. Proc. Nat1. Acad. Sci. 93: 12593-12598.

Miller, K.G., Emerson, M.D., and Rand, J.B. 1999. Go $\alpha$ and diacylglycerol kinase negatively regulate the $\mathrm{Gq} \alpha$ pathway in $C$. elegans. Neuron 24: 323-333.

Nurrish, S., Segalat, L., and Kaplan, J.M. 1999. Serotonin inhibition of synaptic transmission: $\mathrm{G} \alpha(0)$ decreases the abundance of UNC-13 at release sites. Neuron 24: 231-242.

Reynolds, N.K., Schade, M.A., and Miller, K.G. 2005. Convergent, RIC-8-dependent $\mathrm{G} \alpha$ signaling pathways in the Caenorhabditis elegans synaptic signaling network. Genetics 169: 651-670.

Rhee, J.S., Betz, A., Pyott, S., Reim, K., Varoqueaux, F., Augustin, I., Hesse, D., Sudhof, T.C., Takahashi, M., Rosenmund, C., et al. 2002. $\beta$ phorbol ester- and diacylglycerol-induced augmentation of transmitter release is mediated by Munc13s and not by PKCs. Cell 108: 121-133.

Richmond, J.E., Weimer, R.M., and Jorgensen, E.M. 2001. An open form of syntaxin bypasses the requirement for UNC-13 in vesicle priming. Nature 412: 338-341.

Rojas, R.J., Yohe, M.E., Gershburg, S., Kawano, T., Kozasa, T., and Sondek, J. 2007. G- $\alpha$-q directly activates p63RhoGEF and Trio via a conserved extension of the $\mathrm{DH}$-associated $\mathrm{PH}$ domain. J. Biol. Chem. doi: 10.1074/jbc.M703458200.

Schade, M.A., Reynolds, N.K., Dollins, C.M., and Miller, K.G. 2005. Mutations that rescue the paralysis of Caenorhabditis elegans ric-8 (synembryn) mutants activate the $\mathrm{G} \alpha(\mathrm{s})$ pathway and define a third major branch of the synaptic signaling network. Genetics 169: 631-649.

Segalat, L., Elkes, D.A., and Kaplan, J.M. 1995. Modulation of serotonin-controlled behaviors by Go in Caenorhabditis elegans. Science 267: 1648-1651.

Sieburth, D., Ch'ng, Q., Dybbs, M., Tavazoie, M., Kennedy, S., Wang, D., Dupuy, D., Rual, J.F., Hill, D.E., Vidal, M., et al. 2005. Systematic analysis of genes required for synapse structure and function. Nature 436: 510-517.

Sieburth, D., Madison, J.M., and Kaplan, J.M. 2006. PKC-1 regulates secretion of neuropeptides. Nat. Neurosci. 10: 49-57.

Soderling, S.H., Langeberg, L.K., Soderling, J.A., Davee, S.M., Simerly, R., Raber, J., and Scott, J.D. 2003. Loss of WAVE-1 causes sensorimotor retardation and reduced learning and memory in mice. Proc. Natl. Acad. Sci. 100: 1723-1728. 
McMullan and Nurrish

Steven, R., Kubiseski, T.J., Zheng, H., Kulkarni, S., Mancillas, J., Ruiz Morales, A., Hogue, C.W., Pawson, T., and Culotti, J. 1998. UNC-73 activates the Rac GTPase and is required for cell and growth cone migrations in C. elegans. Cell 92: 785795.

Steven, R., Zhang, L., Culotti, J., and Pawson, T. 2005. The UNC-73/Trio RhoGEF-2 domain is required in separate isoforms for the regulation of pharynx pumping and normal neurotransmission in C. elegans. Genes \& Dev. 19: 20162029.

Trent, C., Tsuing, N., and Horvitz, H.R. 1983. Egg-laying defective mutants of the nematode Caenorhabditis elegans. Genetics 104: 619-647.

Wang, L., Li, G., and Sugita, S. 2004. RalA-exocyst interaction mediates GTP-dependent exocytosis. J. Biol. Chem. 279: 19875-19881.

Wettschureck, N. and Offermanns, S. 2005. Mammalian G proteins and their cell type specific functions. Physiol. Rev. 85: 1159-1204.

Wierda, K.D., Toonen, R.F., de Wit, H., Brussaard, A.B., and Verhage, M. 2007. Interdependence of PKC-dependent and PKC-independent pathways for presynaptic plasticity. Neuron 54: 275-290.

Williams, S.L., Lutz, S., Charlie, N.K., Vettel, C., Ailion, M., Cassandra, C., Tesmer, J.J.G., Jorgensen, E.M., Wieland, T., and Miller, K.G. 2007. Trio's Rho-specific GEF domain is the missing $\mathrm{G} \alpha_{\mathrm{q}}$ effector in C. elegans. Genes \& Dev. (this issue). doi: $10.1101 /$ gad.1592007. 


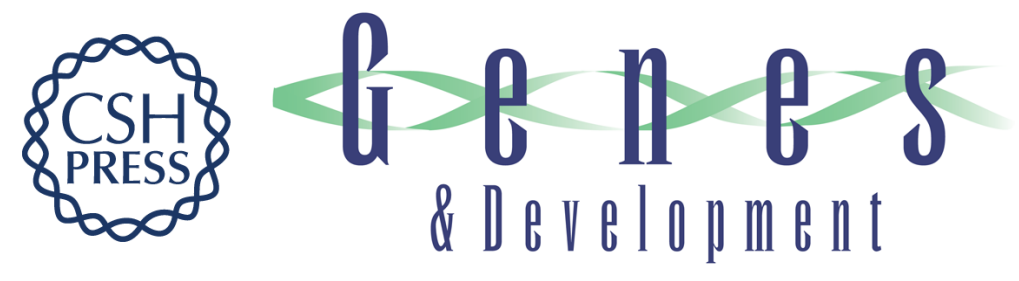

\section{Rho deep in thought}

Rachel McMullan and Stephen J. Nurrish

Genes Dev. 2007, 21:

Access the most recent version at doi:10.1101/gad.1615807

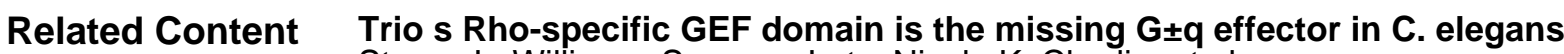
Stacey L. Williams, Susanne Lutz, Nicole K. Charlie, et al. Genes Dev. November , 2007 21: 2731-2746

References This article cites 43 articles, 24 of which can be accessed free at: http://genesdev.cshlp.org/content/21/21/2677.full.html\#ref-list-1

Articles cited in:

http://genesdev.cshlp.org/content/21/21/2677.full.html\#related-urls

\section{License}

Email Alerting

Receive free email alerts when new articles cite this article - sign up in the box at the top Service right corner of the article or click here.

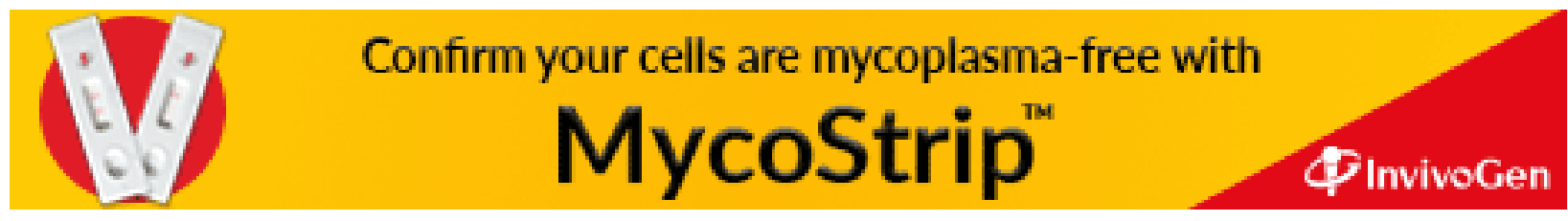

